\title{
Evaluation of high-resolution precipitation analyses using a dense station network
}

\author{
A. Kann ${ }^{1}$, I. Meirold-Mautner ${ }^{1}$, F. Schmid ${ }^{1}$, G. Kirchengast ${ }^{2,3}$, J. Fuchsberger ${ }^{2}$, V. Meyer ${ }^{1}$, L. Tüchler ${ }^{1}$, and B. Bica ${ }^{1}$ \\ ${ }^{1}$ Department of Forecasting Models, Central Institute for Meteorology and Geodynamics (ZAMG), Vienna, Austria \\ ${ }^{2}$ Wegener Center for Climate and Global Change (WEGC), University of Graz, Graz, Austria \\ ${ }^{3}$ Institute for Geophysics, Astrophysics, and Meteorology/Institute of Physics, University of Graz, Graz, Austria
}

Correspondence to: A. Kann (alexander.kann@zamg.ac.at)

Received: 16 September 2014 - Published in Hydrol. Earth Syst. Sci. Discuss.: 21 October 2014

Revised: 17 February 2015 - Accepted: 11 March 2015 - Published: 26 March 2015

\begin{abstract}
The ability of radar-rain gauge merging algorithms to precisely analyse convective precipitation patterns is of high interest for many applications, e.g. hydrological modelling, thunderstorm warnings, and, as a reference, to spatially validate numerical weather prediction models. However, due to drawbacks of methods like crossvalidation and due to the limited availability of reference data sets on high temporal and spatial scales, an adequate validation is usually hardly possible, especially on an operational basis. The present study evaluates the skill of very high-resolution and frequently updated precipitation analyses (rapid-INCA) by means of a very dense weather station network (WegenerNet), operated in a limited domain of the southeastern parts of Austria (Styria). Based on case studies and a longer-term validation over the convective season 2011, a general underestimation of the rapid-INCA precipitation amounts is shown by both continuous and categorical verification measures, although the temporal and spatial variability of the errors is - by convective nature - high. The contribution of the rain gauge measurements to the analysis skill is crucial. However, the capability of the analyses to precisely assess the convective precipitation distribution predominantly depends on the representativeness of the stations under the prevalent convective condition.
\end{abstract}

\section{Introduction}

Reliable precipitation analyses and forecasts with both high temporal update frequency and high spatial resolution are essential for many applications. For example, hydrological models usually require gridded precipitation fields on small scales and short lead times which form the major component of flood warning systems (Komma et al., 2007). In climate research, precipitation re-analyses performed over decades are employed to estimate return periods or other extreme value statistics and often are of high social and economic relevance. Gridded precipitation analyses are also gaining importance in the field of spatial verification of numerical weather prediction (NWP) models, especially since convection-resolving models allow for simulating small-scale convective storms.

A variety of methods exists which aim at generating realistic and skillful precipitation analyses. Goudenhoofdt and Delobbe (2009) have shown that the combination of both radar derived precipitation estimates and rain gauge measurements is superior to the individual fields because particular strengths are emphasized, and weaknesses are compensated. Although it is unquestionable that generally, such combination methods improve the skill of quantitative precipitation analysis, their results strongly depend on the precipitation character, the local environment (e.g. orography), the quality of the radar and rain gauge data, the scale of interest (e.g. for catchment size scales) and the respective application of the precipitation analysis (Rossa et al., 2005). Thus, the impact on validation results of NWP models can be large and should be taken into account (Rezacova and Sokol, 2002) depending on e.g. the radar-rain gauge combination scheme and the diverse application fields. An overview of radar-rain gauge merging algorithms has been elaborated within the COST 717 project (Rossa et al., 2005) - some of them employ bias adjustments schemes (Pereira et al., 1998; Chumchean et al., 2006; Overeem et al., 2009), Kriging approaches (Krajewski, 1987; Sun et al., 2000) also including Bayesian techniques (Handcock and Stein, 1993) and regression-type al- 
gorithms (Gregow et al., 2013). A few merging algorithms are of multi-source nature, including radar and rain gauge data and additional components like NWP data to improve the analysis skill (e.g. NIMROD system by Golding, 1998; INCA system by Haiden et al., 2011).

The Integrated Nowcasting through Comprehensive Analysis (INCA) system has been developed at the Central Institute for Meteorology and Geodynamics in Vienna, Austria (ZAMG) and has been in operational use since spring 2004. Besides precipitation (the most traditional nowcasting parameter) many different parameters are computed by INCA (e.g. precipitation type, temperature, humidity, wind etc.). The techniques for computing analyses and nowcasts vary from parameter to parameter, as well as temporal resolution and update frequency.

A common way of validating the skill of precipitation analyses is the method of leave-one-out cross-validation. However, this method has drawbacks: it is computationally expensive, it assumes a random distribution of the stations with respect to climatology and topography, the results depend on the local conditions of the stations, and - due to the often inhomogeneous and sparse station networks - smallscale features are usually not captured.

Due to its limited representativeness, traditional pointwise verification against station measurements is not adequate and is amended by spatial verification methods like the Structure-Amplitude-Location (SAL) method (Wernli et al., 2008). These novel verification methods require gridded precipitation analyses, preferably model-independent, of high quality as a reference. Wittmann et al. (2010) have used highresolution precipitation analyses to validate the skill of different limited area models (LAM) during a convective season. Similarly, Sattler and Feddersen (2005) have applied daily precipitation analyses to evaluate the quality of a limited area and a global ensemble system during heavy precipitation events.

In this work, the INCA precipitation analyses are validated against the independent data set of the WegenerNet climate station network (operated by the Wegener Centre for Climate and Global Change, University of Graz, Austria; Kirchengast et al., 2014). Rather than the development of new verification measures, this paper applies well-established verification standards (e.g. cross-validation and feature-based metrics) based on this dense station network. The WegenerNet data set has already been successfully applied to validate temperature, humidity, and wind speed analyses in an operational context (Kann et al., 2011). Furthermore, the dense station network allows for a thorough evaluation of INCA precipitation for small-scale, convective precipitation patterns.

Section 2 introduces the rapid-INCA analysis module and the station network WegenerNet. Section 3 briefly illustrates the synoptic conditions of selected cases with heavy precipitation in August and September 2011, and their skill scores of verification. Section 4 describes the results of a long-term validation during the whole convective period from April to September 2011, followed by a conclusion.

\section{Data and methods}

\subsection{The rapid-INCA precipitation analysis}

The rapid-INCA system is an extension of INCA, specifically developed for precipitation nowcasting with a 5-minute accumulation period and update frequency (in contrast to $15 \mathrm{~min}$ in the original INCA version). Radar data from the Austrian weather radar network as well as measurements from the Austrian automatic weather stations network (Teilautomatische Wetterstationen, TAWES) are available every $5 \mathrm{~min}$ and therefore allow for rapid-INCA updates at this frequency. In situations with rapidly changing weather conditions, such as fast-developing thunderstorms, rapid-INCA is a helpful tool (both in analysis and nowcasting mode) as it provides new assessments of the spatial precipitation distribution every $5 \mathrm{~min}$. However, the focus of the present study is on the rapid-INCA analysis procedure, not on nowcasting.

The rapid-INCA precipitation algorithm merges rain gauge measurements from approximately 270 TAWES stations with radar-derived precipitation estimates. The synthesis is designed to combine the strengths of both data sources, i.e. the quantitative accuracy of the station measurements and the detailed spatial information of the radar image. However, the algorithmic synthesis has also to cope with the weaknesses and error sources of both measurement methods and - as far as possible - to compensate for them. These weaknesses are predominantly the potentially low representativeness of site-specific measurements and the general quantitative uncertainty of precipitation estimates from radar reflectivity.

The precipitation analysis consists of the following steps (see Haiden et al., 2011 for a detailed description).

1. Radar-derived quantitative precipitation estimates (QPE): The Austrian radar network consists of two lowland and three mountain radar stations operated by the Austrian aviation service (Austro Control). Each radar scans the atmosphere in $5 \mathrm{~min}$ intervals with 16 customized elevation angles up to an angle of $67^{\circ}$ and to a range of $224 \mathrm{~km}$. A MaxCAPPI (Maximum Constant Altitude Plan Position Indicator) product is provided for each radar station, which is computed from 3-D radar volumes by projecting the maximum value within a vertical column to a 2-D plane. The data are ground clutter corrected by Doppler processing and multitemporal/multi-parameter statistical filters. No further correction on the beam is done, therefore radar-derived products may be influenced by measurement errors, such as bright band, signal attenuation, scan strategy, radar miscalibration, radome wetting, and errors due 


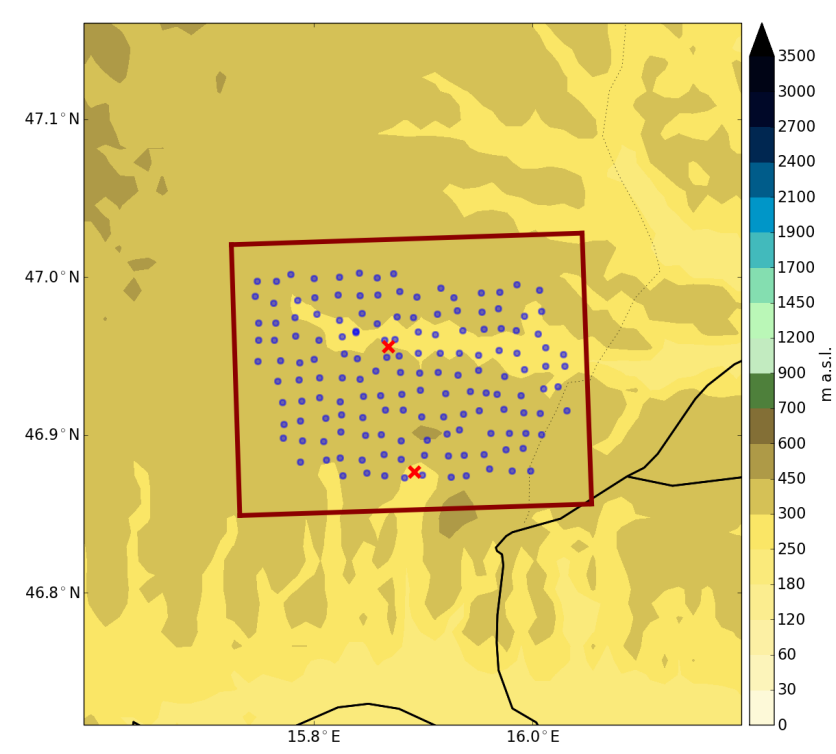

Figure 1. Rapid-INCA topography in the WegenerNet region. Blue circles represent WegenerNet stations, red crosses are the TAWES stations (Teilautomatische Wetterstationen) Feldbach (north) and Bad Gleichenberg (south) of ZAMG.

to non-meteorological echoes. The MaxCAPPI data are provided on a Cartesian grid with a horizontal resolution of $1 \mathrm{~km}$ and reduced to 14 reflectivity classes ("no rain", 11.8, 14.0, 19.5, 22.0, 26.7, 30.0, 34.2, 38.0, 41.8, 46.0, 50.2, 54.3, 58.0 [dBZ]). Reflectivities are operationally converted to rainfall intensities by using the Marshall-Palmer relation $Z=200 R^{1.6}$ (Marshall and Palmer, 1948).

2. Further details about the radar stations and specifications can be found in Kaltenboeck (2012) and Kaltenboeck and Steinheimer (2015). At ZAMG, for lack of radial data, a pattern recognition filter is applied on the MaxCAPPI data to correct R-LAN signals. As the data are only corrected for ground clutter and RLAN, beside residual clutter, all other error sources have to be considered when radar QPE is used. These errors are reflected in the MaxCAPPI data. As in the MaxCAPPI calculation always the maximum value of a vertical column is used - in particular, bright band effects in stratiform rain and the hail core in thunderstorms lead to overestimated rainfall intensities. Other important aspects are partial and total beam shielding and beam broadening with increasing distance to the radar station. In the target region the minimum height which is seen by the radar network is around $2000 \mathrm{~m}$ above ground (Fig. 2b). Rainfall close to the ground, which is measured by ground stations, is not captured in the radar signals, so that potential rainfall intensification or evaporation processes and size sorting due to wind shear on the way to the ground are missed. Furthermore, with the closest radar stations at distances of approx. $100 \mathrm{~km}$ (the mountain site Zirbitzkogel) and approx. $135 \mathrm{~km}$ (lowland site Rauchenwarth) the $1^{\circ}$ beam widths become as broad as 1.7 and $2.35 \mathrm{~km}$, respectively. The large radar bin volumes, together with the high variability of precipitation in space and time, potentially lead to inhomogeneous beam-filling problems and unrepresentative precipitation values. Finally, the fixed $Z-R$ relationship, which does not take into account the variety of different drop-size distributions, and the restricted data resolution of 14 intensity classes are further considerable limitations for radar-predicted rainfall intensities. Still, the MaxCAPPI product is the best available data source for INCA. With all the restrictions of radar-based QPE, radar data have the advantage to capture the precipitation structure in general, so that this information may be added to the local point measurements. INCA reads the MaxCAPPI data provided by each radar and generates a composite by selecting the highest value at each grid point. The MaxCAPPI composite is bi-linearly interpolated onto the INCA grid. A pre-scaling of the radar data is conducted before a high-quality analysis can be calculated as precipitation estimates of the radar may underlie important systematic errors. The local scaling factor results from the ratio of monthly precipitation sums of station interpolation to monthly precipitation sums of radar-derived QPE. To avoid unrealistically high scaling factors a maximum value of 2 is set. In addition to the fixed scaling, a latest-data scaling procedure is applied using recent radar and observation data.

3. Interpolation of rain gauge data: the 1 min measurements are aggregated to $5 \mathrm{~min}$ sums and interpolated by inverse-distance weighting (IDW) onto the $1 \mathrm{~km}$ INCA grid by using the eight nearest stations. Note that only those measurements are used which fulfil several quality control criteria including time series control, comparison with radar data and with neighbouring stations. Figure 2 shows the operational rapid-INCA domain and the distribution of automatic stations as well as the position of the five radar locations.

4. Combination of weather station interpolation and rescaled radar field: the combined field is generated by a weighted relation between both fields and leads to a better precipitation distribution in space than each individual field. It is assured that the observed measurement at the station location is reproduced (within the resolution limits). The larger the distance to the stations, the higher are the weights of the (scaled) radar field. On the other hand, lower radar data quality due to topographic shielding gives higher weight to the interpolated station data. Additionally, elevation effects are parameterized accounting for the increase of precipitation amounts with height (Haiden and Pistotnik, 2009). Figure 3 illustrates the combination algorithm 


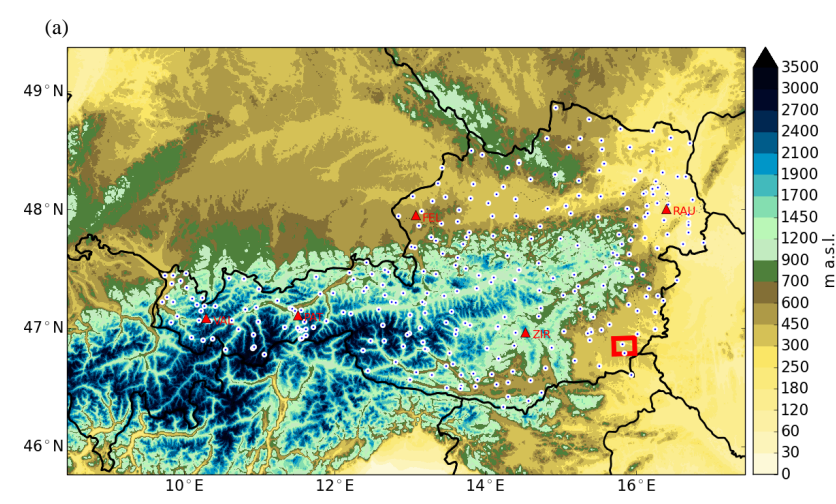

(b)

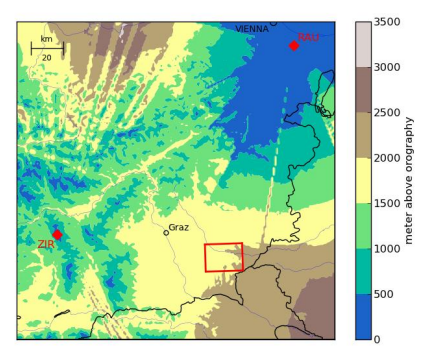

Figure 2. (a) Operational rapid-INCA domain, orography and rain gauge stations (TAWES) measuring precipitation in $5 \mathrm{~min}$ intervals (white/blue dots). Additionally, the locations of the five radars are marked (red triangles) as well as the WegenerNet region (red square). (b) Relative height of the lowest available radar beam above orography, in combination with the location of the WegenerNet (red box) and the locations of the radars Rauchenwarth (RAU) and Zirbitzkogel (ZIR) (red diamonds).

in the case of 13 September 2014, 02:40 UTC. In areas with low radar quality, the combination algorithm assigns large weights to the station interpolation. The radar-derived QPE contributes with small-scale convective cells which were not captured by TAWES stations of ZAMG.

\subsection{The WegenerNet}

This brief description of the station network WegenerNet, operated by the Wegener Center for Climate and Global Change of the University of Graz, Austria, is based on Kirchengast et al. (2014) and Kabas (2012), wherein detailed further information can be found. The WegenerNet comprises $151 \mathrm{me}-$ teorological stations within an area of about $20 \mathrm{~km} \times 15 \mathrm{~km}$ in southeastern Styria, Austria (centred near the city of Feldbach, $46.93^{\circ} \mathrm{N}, 15.90^{\circ} \mathrm{E}$ ), a region with high weather variability (Kabas et al., 2011a, b). The stations are arranged on a quasi-regular $1.4 \mathrm{~km} \times 1.4 \mathrm{~km}$ grid (Fig. 1) and measure the parameters air temperature, relative humidity, and precipitation amount. Selected stations additionally provide measurements of wind and soil parameters. Furthermore, air pressure and net radiation are observed at one reference station. The collected data are processed by the automatic WegenerNet Processing System (WPS). The raw data are stored by Internet loggers (GeoPrecision GmbH, Germany; www.geoprecision.com) and transferred via GPRS to the database at the Wegener Center, Graz. The GPRS transmission is performed hourly, with subsets of about 30 stations transferring in stacked 5 min batches during the first half of the hour.

The incoming data files are stored in a database and are checked by the Quality Control System (QCS). The QCS is run hourly and it checks for each of the 151 stations the availability and correctness as well as the technical and physical plausibility of the measured data in eight quality-control (QC) layers (Table 1).

QC layers 0 and 1 check for data availability, QC layers 2, 5, and 7 are fairly common types of checks, on bounds and deviations, whereas the inter-station check of QC layer 6 , which is made to detect implausible "jumps" of parameter values between stations, is unique to this type of dense station grid. For precipitation data, layers 2, 4, 5, and 6 are key: layer 2 checks for rain rates exceeding sensor specifications, in layer 4 rain rates higher than climatological bounds are detected, and layer 5 looks for inconsistencies between rain gauges at a single station. Layer 6 is able to detect partially or totally blocked funnels, flushes due to sudden opening of blocked funnels, and in general unusual deviations from the values at neighbouring stations. If all QC layers are passed without any detection, the data receive a QC flag of 0 , indicating the highest quality. In the present study, only such flag 0 data were used. Further details about the QCS and all implemented checks can be found in Kirchengast et al. (2014) and Scheidl (2014).

In the Data Product Generator, gridded data of the main parameters are derived on a regular $200 \mathrm{~m} \times 200 \mathrm{~m}$ Universal Transverse Mercator (UTM) grid from individual station measurements by IDW. Subsequently, station data and gridded data (at $5 \mathrm{~min}$ resolution) are also averaged (summed up for precipitation) to various weather and climate data products (from half-hourly up to annual).

For application purposes the resulting data and further information on the station network are available for users at the WegenerNet data portal (www.wegenernet.org) in near-real time (data latency less than 30 to $90 \mathrm{~min}$ ). The WegenerNet provides highly resolved individual station data and regular grids since 1 January 2007 as a new data source for research projects investigating local-scale weather and climate and environmental change. Moreover, the data records serve as information source for various applications in the study region (Kirchengast et al., 2014; Kabas et al., 2011b).

\subsection{Method}

The WegenerNet measurements (5 min precipitation sums) serve as reference in the present study and thus most 


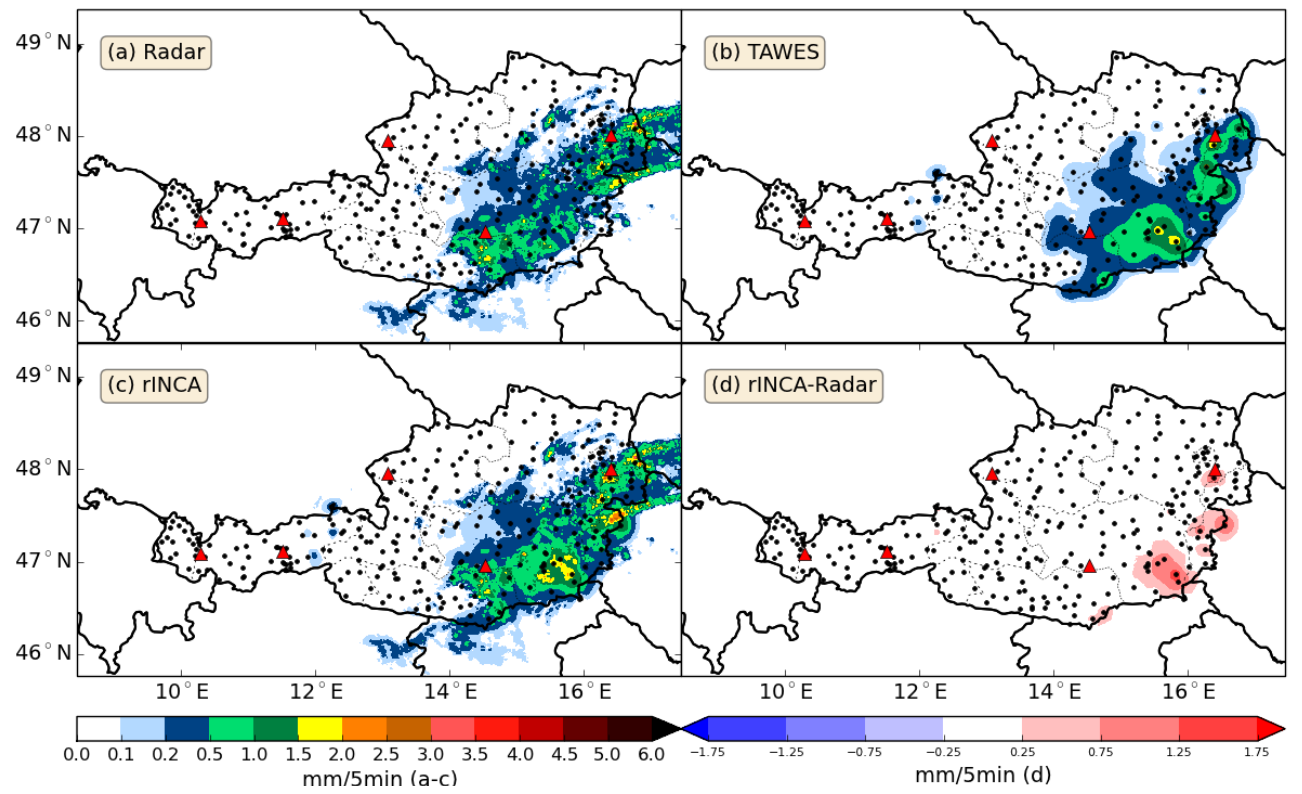

Figure 3. Example of a 5 min precipitation analysis (rapid-INCA) based on the combination of rain gauge data and radar derived QPE on 13 September 2014, 02:40 UTC. (a) Scaled radar field, (b) interpolated rain gauge measurements (TAWES), (c) final rapid-INCA precipitation analysis and (d) difference between rapid-INCA and radar derived QPE.

Table 1. Overview of the WegenerNet data quality-control (QC) layers.

\begin{tabular}{ll}
\hline QC layer & Description \\
\hline 0: check regarding station operation & Check if station is currently in operations \\
1: check of data availability & Check if expected sensor data values are available \\
2: check of sensor functioning & Check if measurement value exceeds permitted range of technical sensor specifications \\
3: check of climatological plausibility & Check if measurement value exceeds plausibly set maximum climatological bounds \\
4: check of temporal variability & Check if measurement value shows too high or too little variation ("jumps", "constancy") \\
5: check of intra-station consistency & Check if measurement value is not properly consistent with related parameters \\
6: check of inter-station consistency & Check if measurement value deviates too much from values at neighbour stations \\
7: check against external reference & Check (for pressure) if measurement value deviates too much from ZAMG reference \\
\hline
\end{tabular}

of the standard comparison techniques are carried out at these station locations. The INCA-related fields, rapid-INCA analyses, radar-derived QPE and rain gauge measurements (TAWES) are interpolated bi-linearly from the $1 \mathrm{~km} \times 1 \mathrm{~km}$ INCA grid to the WegenerNet station locations. This interpolation method has been chosen because the WegenerNet grid is nearly regular with a spatial resolution comparable to the rapid-INCA grid resolution.

Besides bias, mean absolute error (MAE) and root mean squared error (RMSE), the skill scores Equitable Thread Score (ETS), True Skill Score (TSS) and Frequency Bias Index (FBI), which are commonly used for validating precipitation, have been computed for a threshold of $0.5 \mathrm{~mm}$ per 5 min (Table 2).

For spatial comparisons, IDW interpolation has been applied to obtain WegenerNet measurements on the INCA grid. A quadratic distance weighting function has been chosen by taking into account the five nearest neighbours as the station density of WegenerNet in the target region is relatively high and the respective observations should not be smoothed too much. The resulting field has been processed to obtain the spatial verification indicators structure, amplitude and location (SAL; Wernli et al., 2008), but also to demonstrate the spatial patterns of standard verification measures.

\section{Heavy precipitation case studies}

For the selection of cases with heavy precipitation during the convective season of 2011 the definition of Wussow (1922) for integration times smaller than $30 \mathrm{~min}$ has been followed:

$h_{n} \geq \sqrt{5 t-\left(\frac{t}{24}\right)^{2}}$,

where $t$ is the time in minutes and $h_{n}$ the amount of precipitation in millimetres. Thus, a heavy precipitation event 
Table 2. Skill scores used for validation (Wilks, 2006). See also WMO Joint Working Group on Forecast Verification Research, e.g.: http: //www.cawcr.gov.au/projects/verification/.

\begin{tabular}{llll}
\hline & $\begin{array}{l}\text { ETS (equitable } \\
\text { threat score) }\end{array}$ & $\begin{array}{l}\text { True skill score } \\
\text { (TSS) }\end{array}$ & $\begin{array}{l}\text { Frequency bias } \\
\text { index (FBI) }\end{array}$ \\
\hline Range & $-1 / 3$ to 1, 0: no skill & -1 to 1, 0: no skill & 0 to $\infty$ \\
\hline Perfect score & 1 & 1 & 1 \\
\hline $\begin{array}{l}\text { Answers the } \\
\text { question: }\end{array}$ & $\begin{array}{l}\text { How well did the } \\
\text { forecast "yes" } \\
\text { events } \\
\text { correspond to the } \\
\text { observed "yes" } \\
\text { events? }\end{array}$ & $\begin{array}{l}\text { How well did the } \\
\text { forecast separate the } \\
\text { "yes" events from } \\
\text { the "no" events? }\end{array}$ & $\begin{array}{l}\text { How did the } \\
\text { forecast frequency } \\
\text { of "yes" events } \\
\text { compare to the } \\
\text { observed frequency } \\
\text { of "yes" events? }\end{array}$ \\
\hline
\end{tabular}

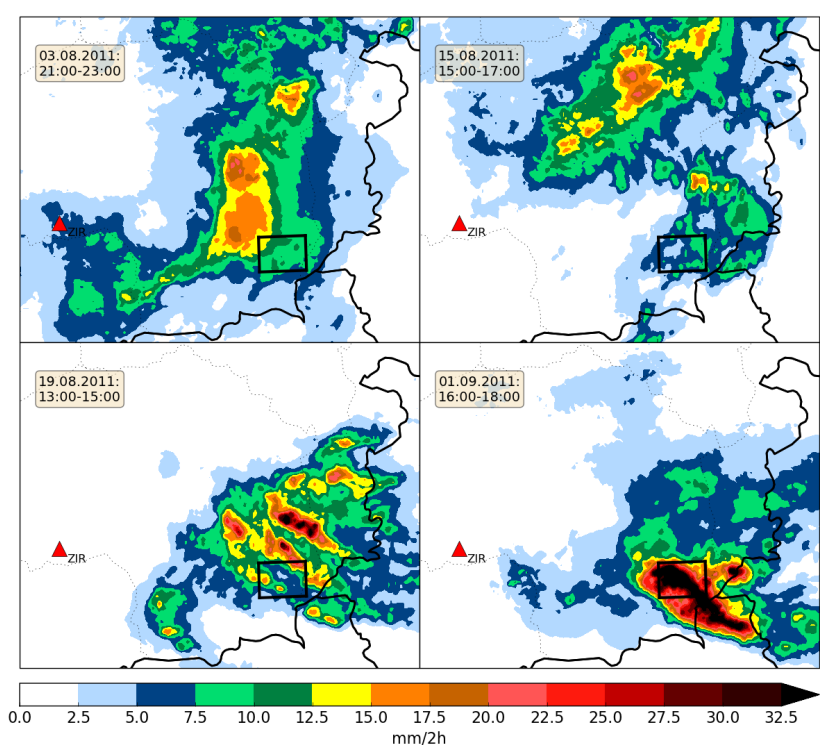

Figure 4. $2 \mathrm{~h}$ precipitation accumulations of the $5 \mathrm{~min}$ rapid-INCA analyses on 4 days (top left: 3 August 2011, top right: 15 August 2011, bottom left: 19 August 2011, bottom right: 1 September 2011) in the respective time spans. The WegenerNet region is marked by a small black rectangle, the red triangle represents the radar (Zirbitzkogel) within this zoom.

is characterized by precipitation amounts exceeding $5 \mathrm{~mm}$ in $5 \mathrm{~min}, 7 \mathrm{~mm}$ in $10 \mathrm{~min}$ or $12 \mathrm{~mm}$ in $30 \mathrm{~min}$.

\subsection{Synoptic situations}

Four cases with heavy precipitation over the WegenerNet region were selected. Figure 4 shows $2 \mathrm{~h}$ sums of the $5 \mathrm{~min}$ rapid-INCA analyses of these selected cases. The synoptic situation for each of the cases is illustrated in Fig. 5.

3 August 2011, 21:00-23:00 UTC: a trough northwest of Ireland and high pressure centred over the Baltics bring a warm upper-level flow from the southwest into Austria. At 18:00 UTC an eastwards-propagating ridge in relative
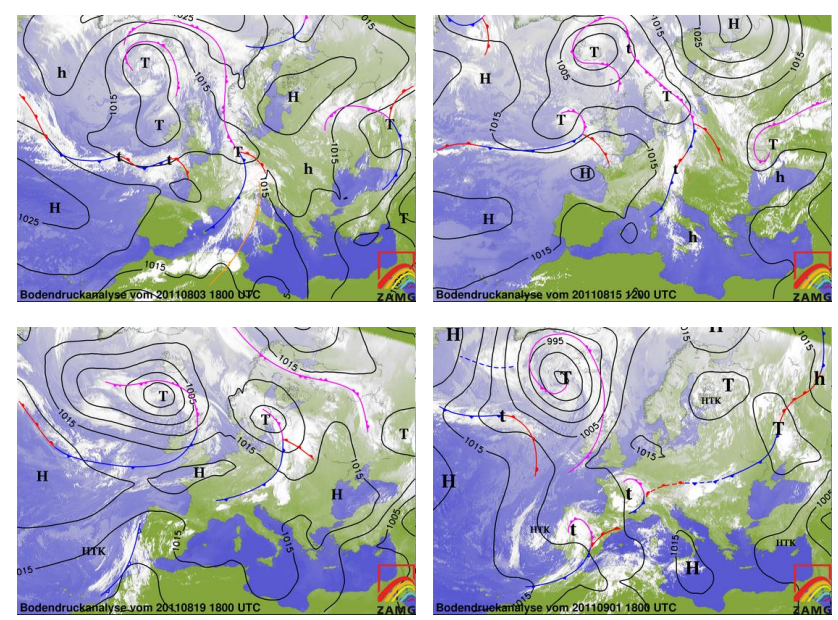

Figure 5. Satellite image, surface pressure analysis and frontal zones on the 4 selected days. Top left: 3 August 2011, 18:00 UTC; top right: 15 August 2011, 12:00 UTC; bottom left: 19 August 2011, 18:00 UTC; bottom right: 1 September 2011, 18:00 UTC.

topography (represented by the orange line in Fig. 5, top left) indicates high values of temperature and humidity in the southeastern part of Austria. CAPE values in the WegenerNet area amount to more than $2000 \mathrm{~J} \mathrm{~kg}^{-1}$ and the lifted index (LI) is around $-6 \mathrm{~K}$, thus indicating a potential for convective developments. A convergence line gradually approaches from the west and leads to the formation of thunderstorms in the western Alpine regions of Austria but also in the southeastern parts of the country.

15 August 2011, 15:00-17:00 UTC: the surface pressure analysis at 12:00 UTC (Fig. 5, top right) shows a lowpressure system centred over Iceland, with secondary lows over southern Sweden and Ireland, whereas rather high pressure and weak gradients prevail over large parts of central Europe. A cold front associated with the trough over southern Sweden crosses Austria in the course of the day. At 15:00 UTC, INCA temperature analyses show temperatures above $30^{\circ} \mathrm{C}$ in the easternmost parts of Austria (33 ${ }^{\circ}$ in west- 


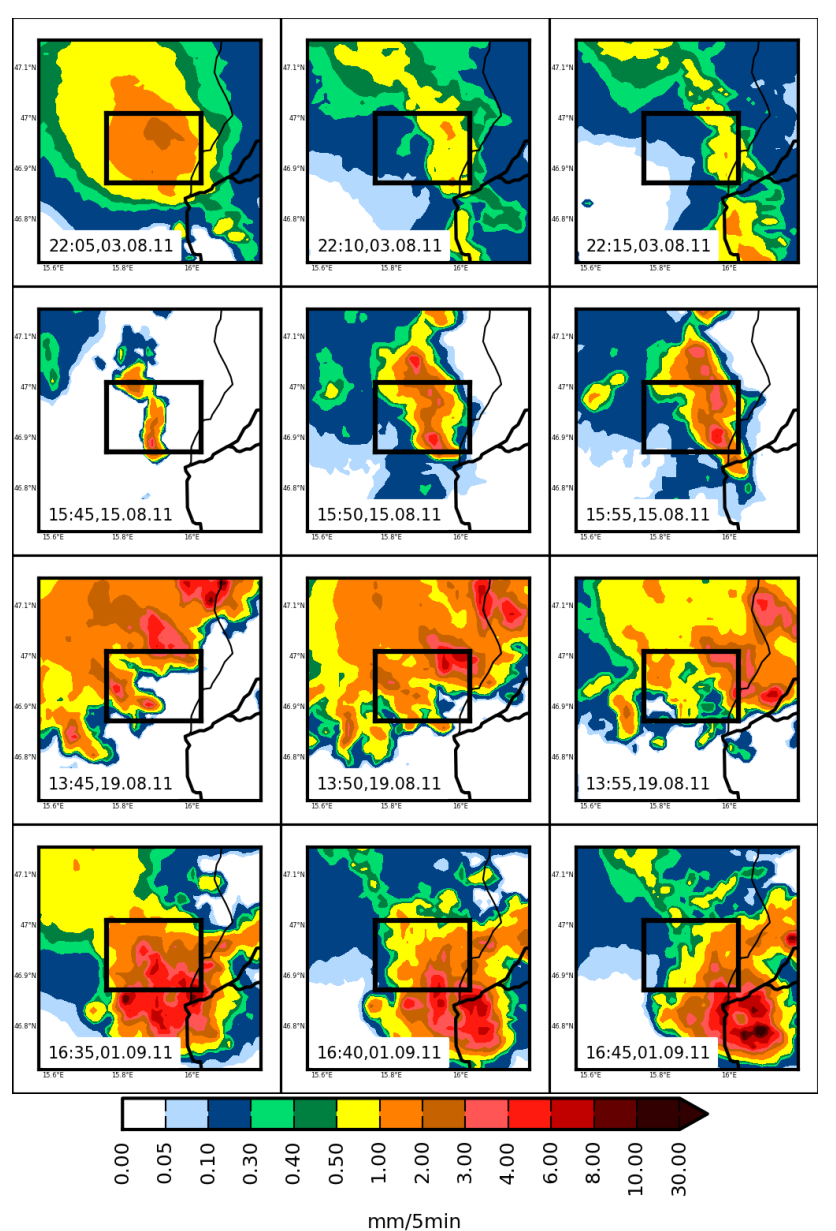

Figure 6. Spatio-temporal distribution of rapid-INCA precipitation $(\mathrm{mm} / 5 \mathrm{~min})$ in the region of the WegenerNet indicated by the black rectangle (time is given in UTC).

ern Hungary) and below $16^{\circ}$ only a few kilometres west of the WegenerNet. A few hours ahead of the event, Deep Layer Shear (DLS) values range to approximately $12 \mathrm{~m} \mathrm{~s}^{-1}$ according to the 03:00 UTC sounding at the $40 \mathrm{~km}$ distant station "Graz Thalerhof" (WMO ID 11240). CAPE (2000 J kg-1) and LI $(-4 \mathrm{~K})$ values at 15:00 UTC are highest within the Alpine region.

19 August 2011, 13:00-15:00 UTC: a cold front associated with a low over the southern Baltic Sea approaches the northern Alpine rim from the northwest (Fig. 5, bottom left), with its forward motion being gradually decreased. Nevertheless, cold air is advected in higher levels, whereas a northerly low level jet with a maximum in $925 \mathrm{hPa}$ brings warm moist air into the target area. Thunderstorms were widespread on that day. In the vicinity of the WegenerNet, DLS values were around $10 \mathrm{~m} \mathrm{~s}^{-1}$ and CAPE close to $1400 \mathrm{~J} \mathrm{~kg}^{-1}$ in the afternoon.

1 September 2011, 16:00-18:00 UTC: a very shallow surface pressure distribution with weak frontal signals domi-
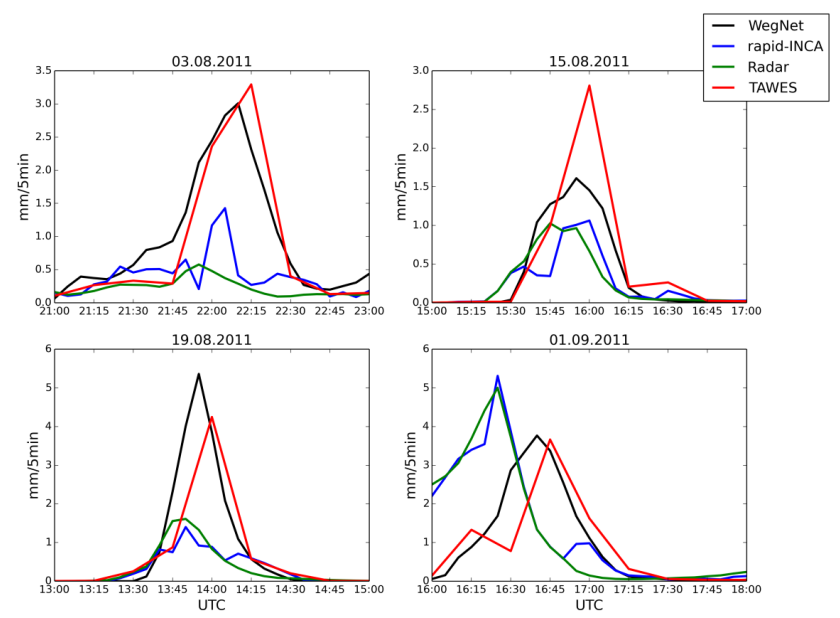

Figure 7. Temporal evolution of precipitation rates for WegenerNet (WegNet), rapid-INCA, radar derived QPE (Radar), and TAWES station and four selected cases.

nates over most parts of Central and Eastern Europe. The air mass over the WegenerNet was generally moist and unstable with an increased potential for convective developments (LI around $-4 \mathrm{~K}, \mathrm{DLS}=12 \mathrm{~m} \mathrm{~s}^{-1}$ ). The thunderstorm initiation might be attributed to a recent crossing of a weak warm front in the northerly direction: in the warm sector the advection of warm air aloft is gradually cut off while the forcing at the ground is given through radiative heating.

\subsection{5-minute rapid-INCA analyses for the selected cases}

Figure 6 shows the spatio-temporal distribution of 5-minute rapid-INCA precipitation analyses in the region of the WegenerNet which is indicated by the black rectangle. On 3 August 2011, the maximum precipitation amounts are between 2 and $3 \mathrm{~mm}$ per $5 \mathrm{~min}$ at 22:05 UTC, and then decrease with time. The precipitation cells on 15 August 2011 are gradually expanded and intensified with time to $6 \mathrm{~mm}$ per 5 min. On 19 August 2011, a heavy precipitation cell moves slowly across the northern part of the WegenerNet area, and on 1 September 2011, extremely high precipitation amounts are reached $(>10 \mathrm{~mm} / 5 \mathrm{~min})$ before the precipitation cells leave the WegenerNet domain to the southeast.

\subsection{Time series and verification of rapid-INCA analyses for the selected cases}

The precipitation rates (per five minutes) of WegenerNet measurements, rapid-INCA, radar-derived QPE, and TAWES station measurements have been averaged over the WegenerNet domain to show the temporal evolution of the precipitation cells in the four selected cases (Fig. 7). Within the WegenerNet area, only two TAWES stations are located (see Fig. 1) and contribute to the interpolated stations field. 


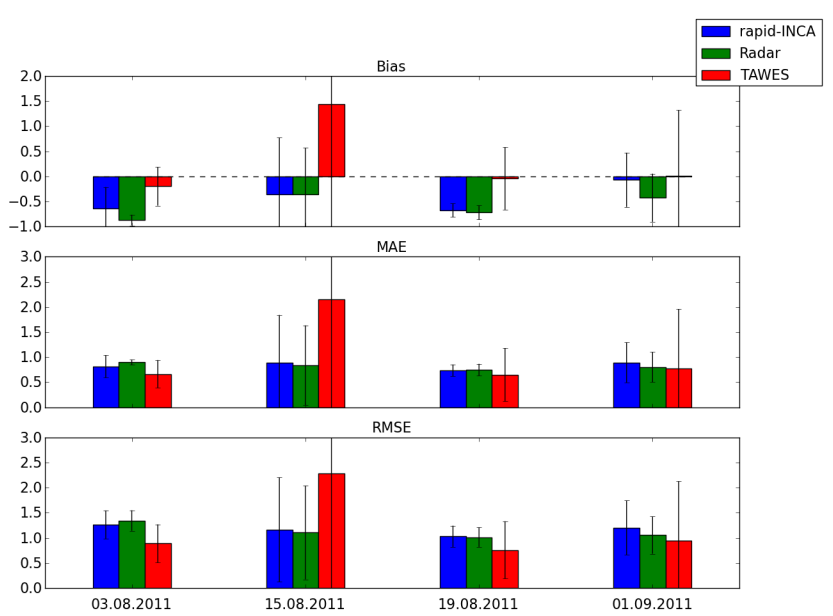

Figure 8. Relative bias, MAE and RMSE (weighted by the mean observed precipitation of WegenerNet). Values have been computed for each of the WegenerNet stations (151 stations) and then averaged over space. Error bars represent the standard deviation of obtained verification measures at each WegenerNet station.

Predominantly, both the onset and evolution of rapid-INCA precipitation amounts follow the WegenerNet observations. However, rapid-INCA underestimates the average precipitation rate in three of the cases, and shows an earlier onset and overestimation in the last case (1 September 2011). The latter situation is triggered by a slight overestimation of radar-derived QPE.

On the first 3 example days, widespread rain systems with embedded intensified precipitation regions and convection cross the target region from southwest/west. In these cases, signal attenuation in the extensive rain regions between radar station and target region and wetted radomes can contribute to the underestimated rain intensities in the radar QPE. On 1 September 2011, mainly one intense thunderstorm with severe hail at the ground is observed crossing the target region. The rainfall overestimation in this case may be attributed to uncorrected hail signals while the signal attenuation is negligible. Even if this simple validation approach is not suitable for a detailed quantitative analysis, it gives a qualitative view of the four cases under investigation.

The verification measures of relative bias, MAE and RMSE (scaled by the mean observed precipitation at each of the WegenerNet stations) have been computed and averaged over space to evaluate the error characteristics of rapidINCA. Only time steps with a minimum observed precipitation of $0.1 \mathrm{~mm} / 5 \mathrm{~min}$ have been selected for the computations. Figure 8 shows the resulting error measures along with the standard deviation indicated by the error bars. A negative bias is visible for all rapid-INCA constituents except for the TAWES station interpolation on 15 August 2011. This is in accordance with the findings in Fig. 7. The error measures MAE and RMSE are similar for rapid-INCA and radarderived QPE, indicating that the radar-derived QPE errors

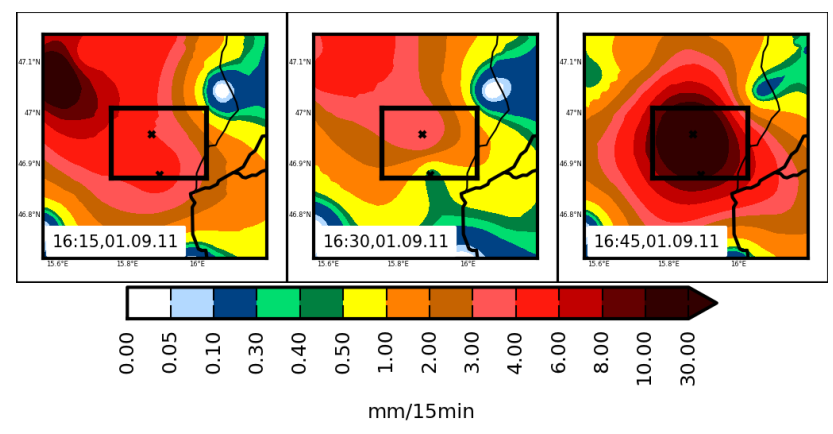

Figure 9. Spatio-temporal distribution of $15 \mathrm{~min}$ interpolated TAWES station measurements $(\mathrm{mm} / 15 \mathrm{~min})$ on 1 September 2011 between 16:15 and 16:45 UTC (region of WegenerNet is shown by the black rectangle and the two TAWES stations of ZAMG are marked with a cross).

predominantly contribute to the rapid-INCA analysis errors. In certain cases (e.g. 15 August 2011 and 1 September 2011), the rapid-INCA analysis error is larger than the radar-derived QPE error. This indicates that the inclusion of the TAWES station observations may decrease the skill, i.e. the TAWES station observations are not representative for this specific precipitation event.

Moreover, the variation in the error measures across the WegenerNet domain is large for the TAWES stations, specifically on 15 August 2011 (only two TAWES stations are located within the WegenerNet area and constitute the interpolated stations field; see Fig. 1). The comparison with the WegenerNet stations results in high variability of bias, MAE and RMSE on 15 August 2011 and 1 September 2011, which demonstrates the low representativeness of the TAWES station field. In such cases, the rapid-INCA analysis (i.e. combination of station interpolation and radar-derived QPE) yields worse error measures than the pure radar-derived QPE. The high variability of rain gauge measurements (TAWES) can also be seen in the spatio-temporal distribution as shown in Fig. 9. The two TAWES stations are hit by a heavy (localized) precipitation cell on 1 September 2011 at 16:45 UTC, and the interpolation results in an exaggeration of the precipitation field (compared to the rapid-INCA analysis in Fig. 6). In this case, an IDW interpolation with an exponent higher than 2 (instead of $1 / r^{2}$ ), would limit the spatial influence of the TAWES stations and improve the results in regimes with local convection.

Averaged skill scores, FBI, TSS and ETS (for a threshold of $0.5 \mathrm{~mm} / 5 \mathrm{~min}$ at WegenerNet stations) are shown in Fig. 10. In the case of low representativeness of the TAWES station interpolation (1 September 2011), the scores FBI and ETS from radar-derived QPE yield better values than those of rapid-INCA. Hence, the station contribution is decreasing the skill. However, in the majority of cases, the skill of rapid-INCA is higher than of pure radar-derived QPE. Higher thresholds than $0.5 \mathrm{~mm} / 5 \mathrm{~min}$ lead to worse results of the 


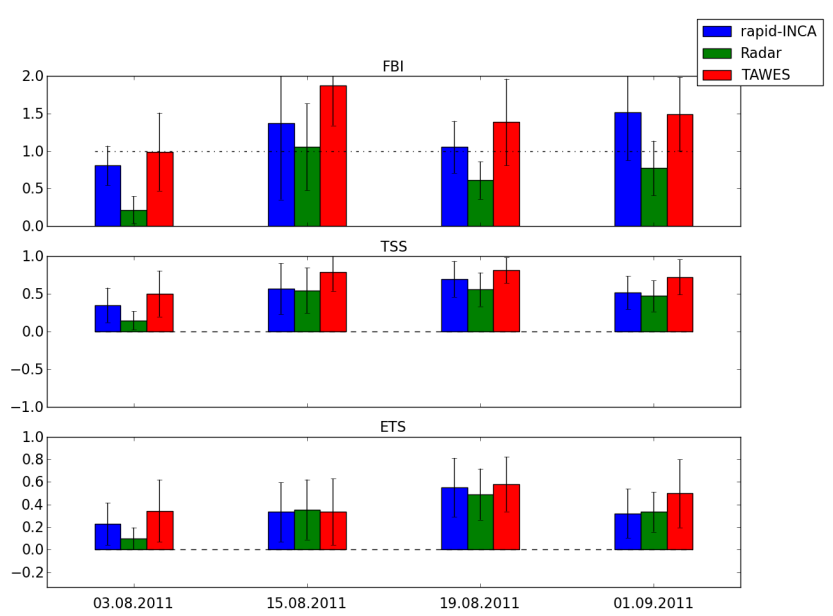

Figure 10. Skill scores for threshold of $0.5 \mathrm{~mm} / 5 \mathrm{~min}$. Scores are computed at each WegenerNet station and then averaged over space. Error bars indicate the standard deviation of the scores.

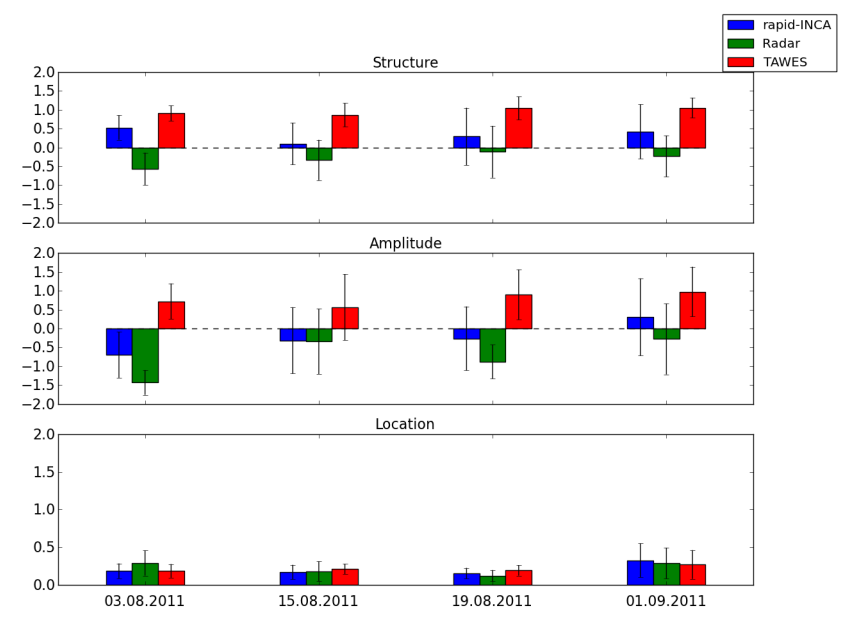

Figure 11. Structure, amplitude and location computed for each time step within the $2 \mathrm{~h}$ intervals at each date and subsequently averaged. Error bars indicate the standard deviation of S, A, L time series.

scores which can partly be explained by the decreasing sample size. Another reason might be the tendency to miss heavy precipitation events with rapid-INCA.

For an objective analysis of the four cases, we applied the structure-amplitude-location (SAL) method (Wernli et al., 2008) to each time step within the respective $2 \mathrm{~h}$ intervals. The results are averaged and plotted in Fig. 11 with error bars indicating the standard deviation of the SAL time series. As already emphasized in previous figures, the amplitude values of rapid-INCA show an underestimation of the observed precipitation in all but one case. Radar-derived QPE exhibits a higher underestimation than rapid-INCA which demonstrates the positive effect of merging interpolated rain gauge measurements (TAWES) with data of radar QPE. Only on 1 September 2011 did the TAWES station data signifi- cantly overestimate precipitation, and in turn overcompensate the radar-derived QPE underestimation to finally yield a positive amplitude value of rapid-INCA. Positive structure values indicate too large and/or too flat precipitation cells. Rapid-INCA overestimates the extent of precipitation cells (on average, as does the TAWES station interpolation). Radar-derived QPE in contrast yields negative structure values, and thus underestimates the extent of the cells. These results suggest that the interpolation method of rain gauge measurements (TAWES) should take into account the current convective situation to be more confined for cases of heavy precipitation (e.g. IDW with a higher exponent, or more sophisticated interpolation methods such as Kriging by using radar data fingerprints).

The location indicator of Fig. 11 does not yield conclusive results as it is relatively low for each of the rapid-INCA constituents. This behaviour may be explained by the small area under investigation and thus limited errors in displacement of cells.

\section{Long-term validation results using WegenerNet data as reference}

For the long-term validation, rapid-INCA analyses, radarderived QPE and interpolated TAWES station measurements from the convective season in 2011 (1 April 2011 to 30 September 2011) at $5 \mathrm{~min}$ time steps have been interpolated to the WegenerNet stations (see Sect. 2.3). The relative bias, MAE and RMSE (scaled by mean measured WegenerNet precipitation) have been computed for each of the WegenerNet stations and, for better spatial representation, interpolated to the INCA domain (by IDW).

Only time steps with measured WegenerNet precipitation exceeding a certain threshold have been used to avoid falsifying the error measures with precipitation-free time steps. Figure 12 presents the results for a selected threshold of $0.5 \mathrm{~mm} / 5 \mathrm{~min}$.

The bias shows substantial underestimation of the radarderived QPE, with no specific spatial variation. Of course, interpolated rain gauge measurements exhibit a better agreement to observations in the vicinity of the two TAWES stations than elsewhere. The rapid-INCA field also shows an underestimation of precipitation higher than $0.5 \mathrm{~mm} / 5 \mathrm{~min}$ but with better results near the stations. In particular, the TAWES station of Feldbach (further north) has a positive impact on the bias of rapid-INCA. Note that the larger positive bias at one location in the northern part of the area is due to erroneous measurements of the corresponding WegenerNet station.

MAE and RMSE are similar error measures and also show similar characteristics in Fig. 12. With RMSE emphasizing large errors, the spatial distribution of the errors is more pronounced. Again, no significant spatial variation can be indicated for radar-derived QPE, whereas interpolated TAWES 


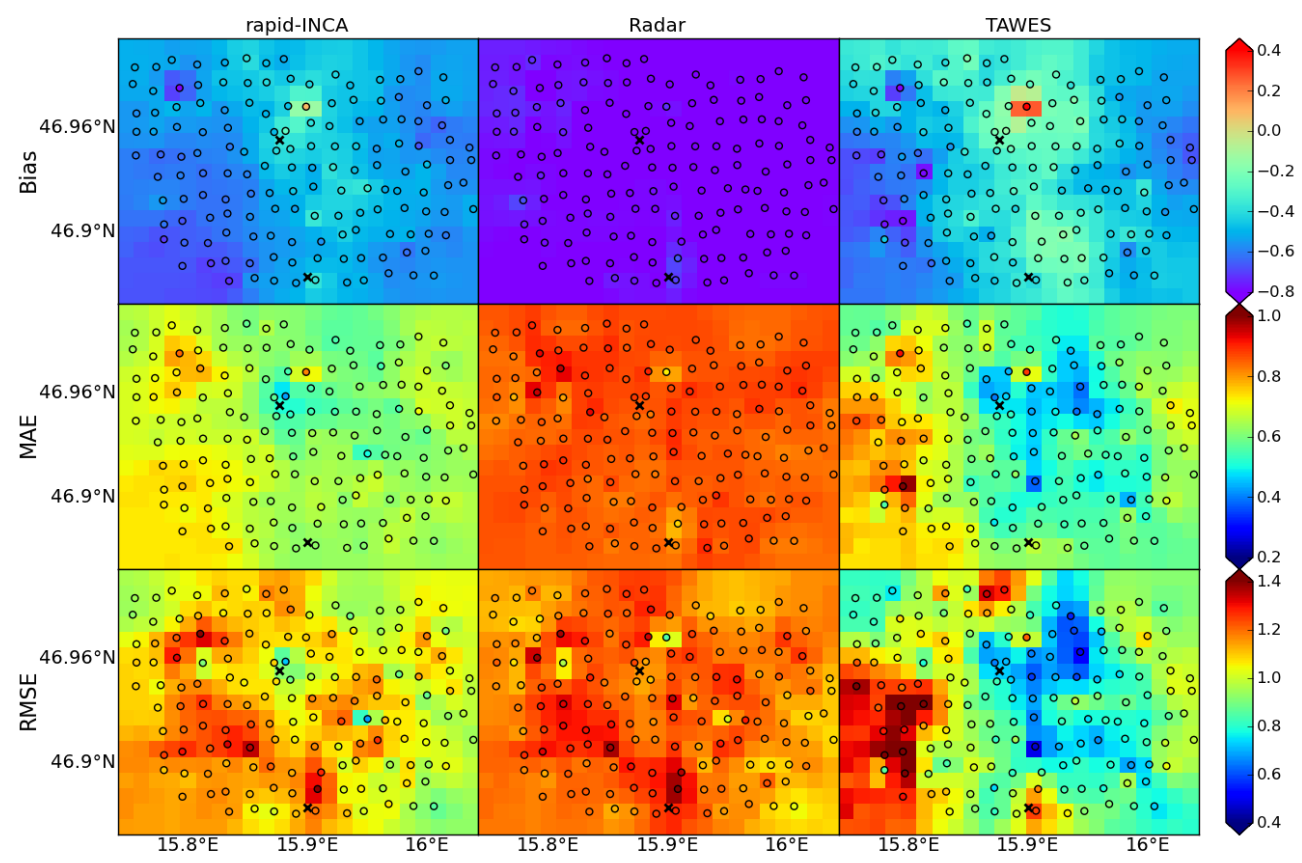

Figure 12. Relative bias, MAE and RMSE for rapid-INCA, radar and TAWES stations at each WegenerNet station. Only those data points are included where the WegenerNet station measured more than $0.5 \mathrm{~mm} / 5 \mathrm{~min}$. Circles represent exact values at the WegenerNet stations; the image is obtained by IDW interpolation to the INCA grid.

station data and rapid-INCA exhibit a better performance around the Feldbach station. The TAWES station further south (Bad Gleichenberg) yields worse results which may be attributed to the topography in this region: Bad Gleichenberg is surrounded by hills to the north, east and west (Fig. 1). With the closest radars as far as 100 and $135 \mathrm{~km}$ away, the large scan volumes in the areas of interest reduce the spatial variability which can be resolved in the radar measurement. The minimum visible height of $2000 \mathrm{~m}$ above ground adds further estimation errors for ground precipitation. But local differences cannot be attributed to local beam shielding effects (compare Fig. 2b).

Figure 13 shows the skill score results for a threshold of $0.5 \mathrm{~mm} / 5 \mathrm{~min}$. Obviously, there is a tendency to underestimate the precipitation amounts (FBI $<1$ ) for all components; the best results for FBI are obtained close to the TAWES station of Feldbach. TSS indicates more hits than misses (TSS closer to 1) near the stations. ETS yields best results for the rapid-INCA analysis.

To investigate the influence of the threshold on the error measures and skill scores, mean values of the error measures and skill scores have been calculated for several thresholds (Fig. 14). The bias of rapid-INCA increases for increasing thresholds of the selected data. Thus, there is a pronounced underestimation of heavy precipitation events. Interpolated rain gauge measurements yield a lower negative bias compared to rapid-INCA which can be attributed to the relatively better performance near the stations, whereas rapid-INCA shows a spatially more homogeneous distribution of the bias (compare Fig. 12). Generally, the variation in error measures and skill scores for the TAWES station data is much higher than for rapid-INCA analysis and radar-derived QPE. Averaging over the WegenerNet domain can lead to better performance of the error measures and skill scores.

Note that the MAE increases with the threshold whereas the RMSE is decreasing. This behaviour indicates that large errors mostly occur for samples including light precipitation amounts (with RMSE putting higher weight on outliers). The coarse resolution of the radar data with a minimum detected signal of $11.8 \mathrm{dBZ}$ (approximately $0.2 \mathrm{~mm} \mathrm{~h}^{-1}$ ) and the reduced visibility in the target region can be reasons for the underestimation of light precipitation in rapid-INCA analyses.

For thresholds of up to $1 \mathrm{~mm}$ (FBI), $0.5 \mathrm{~mm}$ (TSS) and $0.2 \mathrm{~mm}$ (ETS) the skill scores show best results for rapidINCA. At higher thresholds the TAWES stations exhibit better scores than the combined product. During heavy precipitation events, the interpolated rain gauge measurements usually overestimate the spatial precipitation amount and yield better scores than the radar-derived QPE which usually underestimates the precipitation field. Additionally, the merging of radar QPE and TAWES station data consists of non-linear algorithms which cause rapid-INCA to converge to the radar QPE for heavy precipitation (due to the nonrepresentative behaviour of rain gauge measurements during convective events). As long as no hail effects are involved in the measurement, it is likely that convective rainfall intensities are underestimated in the radar QPE due to the fixed 


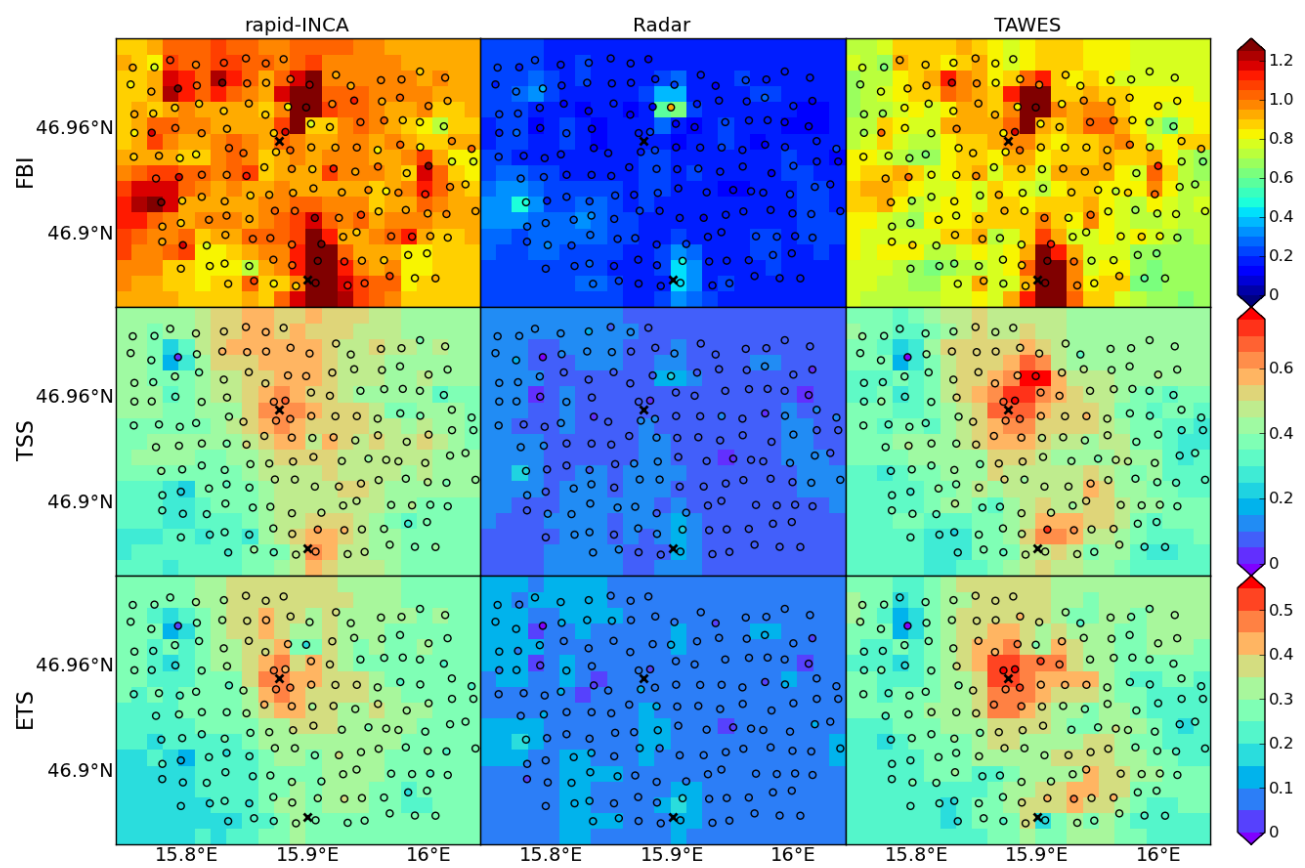

Figure 13. Skill scores for rapid-INCA, radar and TAWES stations at each WegenerNet station. Circles represent the exact values; the image is obtained by interpolation to the INCA grid.
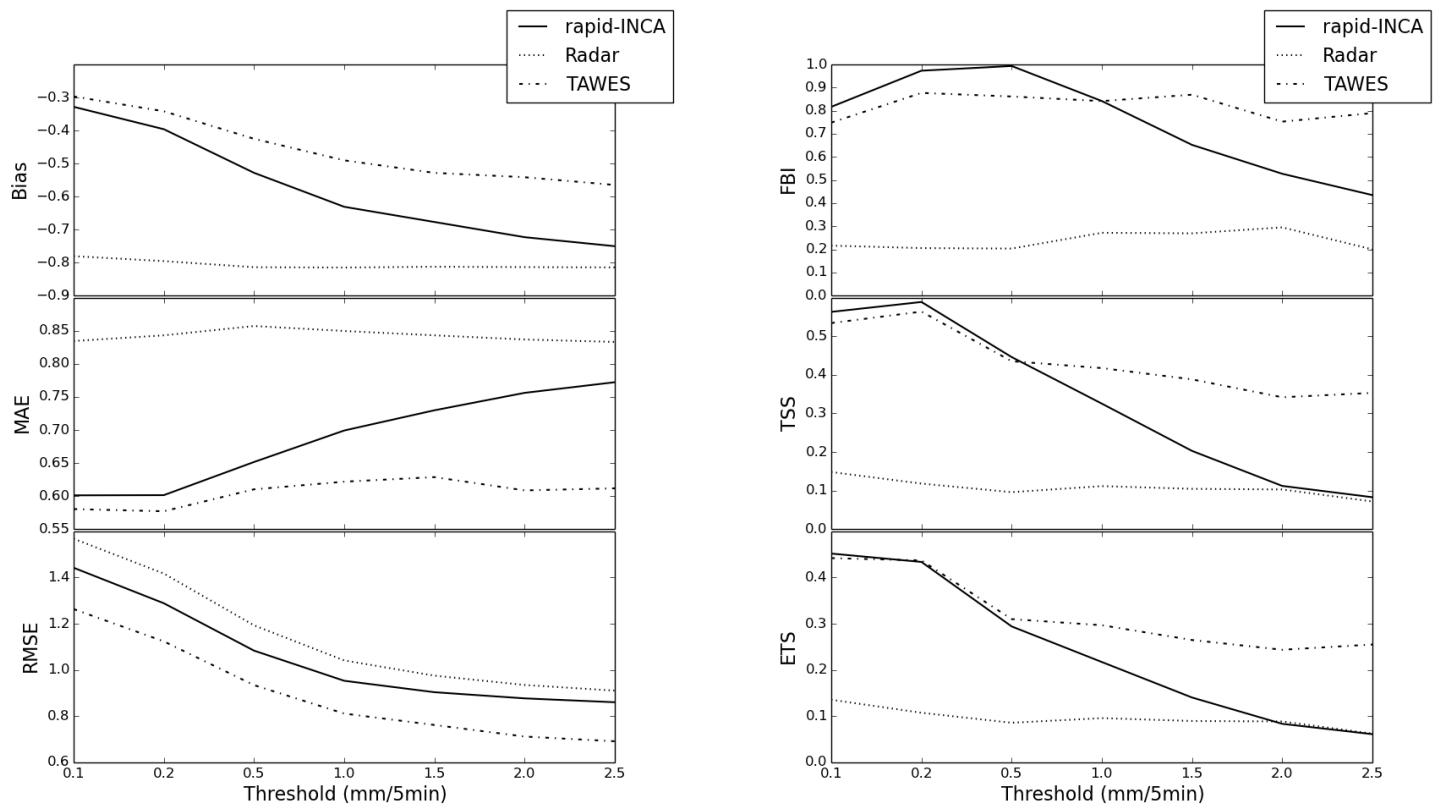

Figure 14. Mean relative error scores (bias, MAE, RMSE) and mean skill scores (FBI, TSS, ETS) computed for several thresholds.

Marshall-Palmer relation, which is used to convert radar reflectivities to rainfall intensities. It has been concluded in several studies that different rain types would need different $Z-$ $R$ relationships (Austin, 1987; Atlas et al., 1999; Steiner et al., 2004). The Marshall-Palmer relation has been found to yield good results in stratiform rain, but can fail in convective rain (Foote, 1966; and following from the findings in Austin, 1987; Steiner et al., 2004). 


\section{Conclusions}

In this study, the performance of short-duration, highresolution precipitation analyses has been elaborated by means of a set of convective events and a long-term validation covering the convective season in 2011 (1 April 201130 September 2011). In order to point out the small-scale features of convective events, the dense station network of WegenerNet, which is located in the southeastern parts of Austria (Styria), has been used as a reference.

The validation results show a general underestimation of rapid-INCA and its constituents (radar-derived QPE and rain gauge measurements of TAWES). The spatial variation in error measures is highest for the interpolated TAWES station data. Results from the four selected cases in August and September 2011 show that the contribution from TAWES station interpolation can either have a positive or negative impact on the rapid-INCA skill, depending on the representativeness of the station measurements. Merging TAWES station data with radar-derived QPE is able to reduce this effect, but is not able to avoid it completely. Another reason for the underestimation might be the tendency to miss heavy precipitation with rapid-INCA.

This study indicates that the station contributions play a crucial part in the performance of the rapid-INCA analyses or in general in any radar-gauge merging method. Depending on the prevalent synoptic situation, e.g. local convection or large-scale precipitation, it may prove useful to adapt the station interpolation algorithm accordingly. Instead of a static IDW with both a fixed number of included nearest stations and a fixed exponent it could be advantageous to apply an IDW with dynamically adjusted parameters. Thus, further studies are needed to investigate the influence of IDW parameters as well as modifications in the combination algorithm on the validation results. Also an improved pre-scaling of radar QPE may be useful since radar QPE shows a strong underestimation over the whole data set. As was outlined in detail 35 years ago in Wilson and Brandes (1979) and more recently in Krajewski et al. (2010), radar QPE is prone to a number of measurement errors.

For rapid-INCA analyses, the MaxCAPPI product is used as the best available information source. As the data are only corrected for ground clutter and R-LAN, beside residual clutter, all other error sources have to be considered when radar QPE is used. Topographically complex domains will always face the problem of locally reduced radar visibilities and elevated radar locations on mountain massifs. However, the recent upgrade of the Austrian radar network to dual-pol technology provides possibilities for more sophisticated methods of quality control and data correction, which promise more accurate radar QPE products. Apart from further improvements by applying more sophisticated radar-rain gauge blending methods, the quantification of the uncertainties related to the representativeness problem is a key issue in the generation of an ensemble of precipitation analyses.
The present study reveals that the WegenerNet, which offers high-quality station measurements on very high temporal and spatial resolution, is ideally suited to further improve precipitation analyses and to assess their skill and uncertainty.

Acknowledgements. The authors thank Martin Suklitsch, Christine Gruber and Robert Goler for fruitful discussions about scientific and operational issues, and the editor and two anonymous referees for fruitful comments that led to substantial improvements of the paper.

Edited by: U. Ehret

\section{References}

Atlas, D., Ulbrich, C. W., Marks Jr., F. D., Amitai, E., and Williams, C. R.: Systematic variation of drop size and radar-rainfall relation, J. Geophys. Res., 104, 6155-6169, 1999.

Austin, P. M.: Relation between Measured Radar Reflectivity and Surface Rainfall, Mon. Weather Rev., 115, 1053-1070, 1987.

Chumchean, S., Sharma, A., and Seed, A.: An Integrated Approach to Error Correction for Real-Time Radar-Rainfall Estimation, J. Atmos. Ocean. Technol., 23, 67-79, 2006.

Foote, G. B.: A Z-R relation for mountain thunderstorms, J. Appl. Meteorol., 2, 229-231, 1966.

Golding, B. W.: Nimrod: A system for generating automated very short range forecasts, Meteorol. Appl., 5, 1-16, 1998.

Goudenhoofdt, E. and Delobbe, L.: Evaluation of radar-gauge merging methods for quantitative precipitation estimates, Hydrol. Earth Syst. Sci., 13, 195-203, doi:10.5194/hess-13-1952009, 2009.

Gregow, E., Saltikoff, E., Albers, S., and Hohti, H.: Precipitation accumulation analysis - assimilation of radar-gauge measurements and validation of different methods, Hydrol. Earth Syst. Sci., 17, 4109-4120, doi:10.5194/hess-17-4109-2013, 2013.

Haiden, T. and Pistotnik, G.: Intensity-dependent parameterization of elevation effects in precipitation analysis, Adv. Geosci., 20, 33-38, doi:10.5194/adgeo-20-33-2009, 2009.

Haiden, T., Kann, A., Wittmann, C., Pistotnik, G., Bica, B., and Gruber, C.: The Integrated Nowcasting through Comprehensive Analysis (INCA) System and Its Validation over the Eastern Alpine Region, Weather Forecast., 26, 166-183, 2011.

Handcock, M. S. and Stein, M. L.: A Bayesian analysis of Kriging, Technometrics, 35, 403-410, 1993.

Kabas, T.: WegenerNet Klimastationsnetz Region Feldbach: Experimenteller Aufbau und hochauflösende Daten für die Klimaund Umweltforschung, Wiss. Ber. 47, document WCV-WissBerNo47-TKabas-Jan2012.pdf, Wegener Center Verlag, Graz, Austria, available at: http://www.wegcenter.at/wcv/ (last access: 16 February 2015), 2012.

Kabas, T., Foelsche, U., and Kirchengast, G.: Seasonal and annual trends of temperature and precipitation within 1951/19712007 in South-Eastern Styria/Austria, Meteorol. Z., 20, 277-289, 2011a.

Kabas, T., Leuprecht, A., Bichler, C., and Kirchengast, G.: WegenerNet climate station network region Feldbach, Austria: 
network structure, processing system, and example results, Adv. Sci. Res., 6, 49-54, 2011 b.

Kaltenboeck, R.: New generation of dual polarized weather radars in Austria, in: Proceedings of the 7th European Conference on Radar in Meteorology and Hydrology (ERAD), Toulouse, France, 24-29 June 2012, 6 pp., 2012.

Kaltenboeck, R. and Steinheimer, M.: Radar-based severe storm climatology for Austrian complex orography related to vertical wind shear and atmospheric instability, Atmos. Res., 158-159, 216-230, doi:10.1016/j.atmosres.2014.08.006, 2015.

Kann, A., Haiden, H., von der Emde, K., Gruber, C., Kabas, T., Leuprecht, A., and Kirchengast, G.: Verification of operational analyses using an extremely high-density surface station network, Weather Forecast., 26, 572-578, 2011.

Kirchengast, G., Kabas, T., Leuprecht, A., Bichler, C., and Truhetz, H.: WegenerNet: A pioneering high-resolution network for monitoring weather and climate, B. Am. Meteorol. Soc., 95, 227-242, 2014.

Komma, J., Reszler, C., Blöschl, G., and Haiden, T.: Ensemble prediction of floods - catchment non-linearity and forecast probabilities, Nat. Hazards Earth Syst. Sci., 7, 431-444, doi:10.5194/nhess-7-431-2007, 2007.

Krajewski, W. F.: Co-kriging radar-rainfall and raingage data, J. Geophys. Res., 92, 9571-9580, 1987.

Krajewski, W. F., Villarini, G., and Smith, J. A.: RADAR-Rainfall Uncertainties, B. Am. Meteorol. Soc., 91, 87-94, 2010.

Marshall, J. S. and Palmer, W. M.: The distribution of raindrops with size, J. Meteorol., 5, 165-166, 1948.

Overeem, A., Holleman, I., and Buishand, A.: Derivation of a 10-year radar-based climatology of rainfall, J. Appl. Meteorol. Clim., 48, 1448-1463, 2009.

Pereira Fo, A. J., Crawford, K. C., and Hartzell, C. L.: Improving WSR-88D Hourly Rainfall Estimates, Weather Forecast., 13, 1016-1028, 1998.

Rezacova, D. and Sokol, Z.: Results of numerical experiments with LM DWD - First attempts to verify precipitation forecast by radar derived rainfall fields (1998 flood event), COST-717 Working document WDF_02_200204_2, Brussels, 12 pp., 2002.
Rossa, A., Bruen, M., Frühwald, D., Macpherson, B., Holleman, I., Michelson, D., and Michaelides, S.: Use of Radar Observations in Hydrological and NWP Models. ESSEM COST Action 717, Office for Official Publications of the European Communities, Brussels, 292 pp., 2005.

Sattler, K. and Feddersen, H.: Limited-area short-range ensemble predictions targeted for heavy rain in Europe, Hydrol. Earth Syst. Sci., 9, 300-312, doi:10.5194/hess-9-300-2005, 2005.

Scheidl, D.: Improved quality control for the WegenerNet and demonstration for selected weather events and climate. Sci. Rep. No. 61, document WCV-SciRep-No61-DScheidl-Oct2014.pdf, Wegener Center Verlag, Graz, Austria, available at: http://www. wegcenter.at/wcv/ (last access: 16 February 2015), 2014.

Steiner, M., Smith, J. A., and Uijlenhoet, R.: A Microphysical Interpretation of Radar Reflectivity-Rain Rate Relationships, J. Atmos. Sci., 61, 1114-1131, 2004.

Sun, X., Mein, R. G., Keenan, T. D., and Elliott, J. F.: Flood estimation using radar and raingauge data, J. Hydrol., 239, 4-18, 2000 .

Wernli, H., Paulat, M., Hagen, M., and Frei, C.: SAL - A novel quality measure for the verification of quantitative precipitation forecasts, Mon. Weather Rev., 136, 4470-4487, 2008.

Wilks, D. S.: Statistical Methods in the Atmospheric Sciences, 2nd Edn., Academic Press, Burlington, MA; London, 627 pp., 2006.

Wilson, J. W. and Brandes, E. A.: Radar Measurement of Rainfall A Summary, B. Am. Meteorol. Soc., 60, 1048-1058, 1979.

Wittmann, C., Haiden, T., and Kann, A.: Evaluating multi-scale precipitation forecasts using high resolution analysis, Adv. Sci. Res., 4, 89-98, 2010.

Wussow, G.: Untere Grenzwerte dichter Regenfälle, Meteorol. Z., 39, 173-178, 1922. 